\title{
Prevalence of Metabolic Syndrome in Overweight and Obese Patients and Their Measurement of Neck Circumference: A Cross-sectional Study
}

\author{
Ayesha A. Hai ${ }^{1}$, Sundus Iftikhar ${ }^{2}$, Saba Latif ${ }^{1}$, Fivzia Herekar ${ }^{3}$, Sana Javed ${ }^{1}$, Muhammad Junaid Patel ${ }^{1}$
}

1. Internal Medicine, The Indus Hospital, Karachi, PAK 2. Statistics, Indus Hospital Research Center, The Indus Hospital, Karachi, PAK 3. Internal Medicine and Infectious Diseases, The Indus Hospital, Karachi, PAK

Corresponding author: Ayesha A. Hai, ayesha.hai@hotmail.com

\section{Abstract \\ Background}

The utilization of neck circumference (NC) as a valuable tool to evaluate metabolic syndrome (MetS) is still unclear. MetS has been extensively reported worldwide mainly due to the increasing trend of central obesity and the risk of developing coronary artery disease. In Pakistan, its incidence is reported to be between $18 \%$ and $49 \%$ among the urban population.

\section{Methods}

This cross-sectional study was conducted at the Indus Hospital, Karachi, Pakistan; in total, 392 patients (body mass index $[\mathrm{BMI}]>23 \mathrm{~kg} / \mathrm{m}^{2}$, age $\geqslant 18$ years, both genders) were recruited through consecutive sampling, and informed consent was obtained.

\section{Results}

The majority of patients were females ( $n=344,87.8 \%$ ), and the mean \pm SD of age and NC of all patients was $50.5 \pm 9.6$ years and $38 \pm 4.6 \mathrm{~cm}$, respectively. The majority $(n=375,95.7 \%)$ of patients were found to have MetS, with $90 \%$ of both males and females having $\mathrm{NC} \geqslant 38 \mathrm{~cm}$ and $34 \mathrm{~cm}$, respectively.

\section{Conclusion}

The prevalence of MetS was found to be very high in overweight and obese patients. Moreover, the majority of patients with MetS were found to have higher NC.

Received 10/15/2019

Review began 10/17/2019 Review ended 11/04/2019 Published 11/10/2019

๑) Copyright 2019 Hai et al. This is an open access article distributed under the terms of the Creative Commons Attribution License CC-BY 3.0., which permits unrestricted use, distribution, and reproduction in any medium, provided the original author and source are credited.
Categories: Endocrinology/Diabetes/Metabolism, Internal Medicine Keywords: metabolic syndrome, overweight, obese

\section{Introduction}

Globally, the burden of overweight and obesity has been increasing substantially affecting almost 30\% of the entire world population [1]. Overweight and obesity are defined as an excessive accumulation of body fat or weight that exceeds the age- and gender-specific reference limits leading to ill health and a high incidence of non-communicable diseases such as metabolic syndrome (MetS) [1-2]. Pakistan ranks ninth among the world's most obese nations [1].

MetS is a serious health condition that can lead to several chronic, non-communicable diseases such as cardiovascular disease and diabetes mellitus [3]. MetS is a combination of at least three of the following five metabolic abnormalities: 1) elevated waist circumference (cutoff for Asians: $\geqslant 90 \mathrm{~cm} / 35.4$ inches in men and $\geqslant 80 \mathrm{~cm} / 31.5$ inches in women), 2) elevated triglycerides (TG; $\geqslant 150 \mathrm{mg} / \mathrm{dL}$ ), 3) reduced high-density lipoprotein (HDL; $<40 \mathrm{mg} / \mathrm{dL}$ in men and $<50 \mathrm{mg} / \mathrm{dL}$ in women), 4) elevated blood pressure (systolic blood pressure $[\mathrm{SBP}] \geqslant 130 \mathrm{mmHg}$ or diastolic blood pressure [DBP] $\geqslant 85 \mathrm{~mm} \mathrm{Hg}$ ) or hypertensive, and 5) elevated fasting blood glucose level ( $\geqslant 100 \mathrm{mg} / \mathrm{dL}$ or $5.6 \mathrm{mmol} / \mathrm{L}$ ) or diabetic [4].

There are several criteria for diagnosing MetS, of which the National Cholesterol Education Program Adult Treatment Panel III (NCEP ATP III) and the International Diabetes Federation (IDF) are the most widely used criteria in Pakistan due to their reliability [5-6]. According to these criteria, the prevalence of MetS in Pakistan over the last decade is reported to be $35 \%$ to $64 \%$ [7-8]. According to the report of the Global Burden of Disease (GBD), the disability-adjusted life years (DALYs) attributable to risk factors associated with the diagnosis of MetS have dramatically increased over the past two decades [9]. The report revealed that in 2010, high BMI and diabetes ranked sixth among the various leading risk factors and non-communicable diseases contributing to DALYs [9].

Waist circumference (WC) is commonly used to define central obesity and plays a vital role in diagnosing obesity and MetS. The measurement of WC may be significantly influenced by various measuring methods, weather conditions, particularly winter, and interday variations that might affect the abdominal wall and 
abdominal cavity [10]. Literature has shown that the heterogeneity in body structure and abdominal tissues depend on not only age and gender but also ethnicity [11]. Hence, the IDF has now proposed lower cut-off values for WC for some ethnicities [11]. Moreover, BMI, which is considered as another valuable tool to assess overweight and obesity, does not evaluate fat distribution; hence, it cannot always assess the individual risk of endocrine and metabolic complications.

Therefore, several studies have been carried out to assess the alternative anthropometric measure for diagnosing overweight, obesity, and MetS. Recently, researchers have greatly focused on NC, a parameter of upper-body adiposity. NC is a simpler, relatively new and practical anthropometric indicator that is not affected by the postprandial abdominal distension or by respiratory movements and can be particularly useful in specific populations such as morbidly obese people, patients in bed rest, and pregnant women [9].

NC has been shown to be promising in diagnosing overweight and obesity and is also significantly associated with cardiovascular disease, SBP and DBP, and TG, total cholesterol, and fasting blood sugar levels; NC is also a predictor of obstructive sleep apnea syndrome in the Framingham study [7,12-13].

Moreover, recent studies have also reported a significant and positive correlation between NC and MetS [1415]. A study done in Pakistan in 2016 has reported a higher NC in the MetS group in comparison to the nonMetS group [14]. Additionally, the study reported $\mathrm{NC} \geqslant 38 \mathrm{~cm}$ and $\geqslant 34 \mathrm{~cm}$ as the optimal cutoff values for the diagnosis of MetS in males and females, respectively [14]. However, a systematic review and meta-analysis done in 2018 reported significant positive associations between NC and the various factors of MetS but has reported no association between the two [16].

We aimed to conduct this study to assess the prevalence of MetS owing to the dearth of local literature reporting the current burden of MetS in Pakistan. Also, this study intended to gauge the optimal cutoff values of NC provided by Hingorjo MR et al. [17].

\section{Materials And Methods}

This cross-sectional study was conducted at the Indus Hospital, Karachi (TIH), a free-of-cost tertiary care facility. A priori sample size was calculated using OpenEpi software (Open Source Epidemiologic Statistics for Public Health, Version 3.01) with the following assumptions: MetS prevalence of $49 \%$ and the desired precision of 5\% [7]. The required sample size was estimated to be 384. All patients of either gender and age $\geqslant 18$ years presenting to the outpatient clinics or admitted in the medical unit with $\mathrm{BMI}>23 \mathrm{~kg} / \mathrm{m}^{2}$ as per the Asian criteria and had given informed consent were included in the study through non-probability consecutive sampling [18].

Patients with clinical or laboratory evidence of cardiac failure (stage C and D), liver failure, hyper or hypothyroidism, known congenital syndromes that lead to obesity, or on systemic steroids were excluded from the study.

Data on socio-demographic characteristics, such as age, gender, comorbidities, anthropometric variables (height, weight, BMI, NC, WC), and blood pressure, were gathered. MetS screening tool used by the Department of Mental Health, Missouri was used to assess MetS [17]. Recent biochemical profiles of individual patients such as fasting plasma glucose, TC, LDP, TG, and HDP levels were extracted from the Hospital Information Management System (HIMS) of TIH. All data were recorded on a pre-designed questionnaire.

Blood pressure was measured using the auscultatory method, which uses a mercury sphygmomanometer and stethoscope for determining the SBP and DBP based on the appearance and disappearance of Korotkoff sounds, respectively. Two readings for SBP and DBP were taken and their average value was used in the analysis. Anthropometric measurements were measured using a soft flexible measuring tape. WC was measured in centimeters at the midpoint between the lowest rib and the highest point of the iliac crest. NC was measured at the level of the lower part of thyroid cartilage (just below Adam's apple) along a horizontal line in centimeters, with readings up to 1 decimal place.

\section{Data analysis procedure}

Data were entered on REDCap software (RedCap v9.1.0, Vanderbilt University) and analyzed using SPSS version 24.0 (IBM Corp, Armonk, NY). All the quantitative variables such as age, SBP and DBP, and biochemical parameters were assessed for normality and reported as mean \pm SD or median (interquartile range $[\mathrm{IQR}])$ as appropriate. The categorical variables were reported as frequencies and percentages. The prevalence of MetS was calculated using the criteria. Pearson or Kendall Tau-b correlation were used as appropriate to assess the relationship between NC and components of MetS. $P$-value $<0.05$ was considered significant.

\section{Results}

A total of 392 patients were included in the study, and the majority of patients 344 (87.8\%)were females. The mean \pm SD age and NC of all the patients were $50.5 \pm 9.6$ years and $38 \pm 4.6 \mathrm{~cm}$, respectively (Table 1 ). 


\section{Cureus}

\begin{tabular}{|c|c|}
\hline & $\mathrm{n}(\%)$ \\
\hline \multicolumn{2}{|l|}{ Gender } \\
\hline Male & $48(12.2)$ \\
\hline Female & $344(87.8)$ \\
\hline Total & $392(100)$ \\
\hline \multicolumn{2}{|l|}{ Ethnicity } \\
\hline Sindhi & $26(6.6)$ \\
\hline Balochi & $8(2)$ \\
\hline Urdu speaking & $185(47.2)$ \\
\hline Punjabi & $72(18.4)$ \\
\hline Pathan & $35(8.9)$ \\
\hline Others & $66(16.8)$ \\
\hline Total & $392(100)$ \\
\hline \multicolumn{2}{|l|}{ Occupation } \\
\hline Professional & $11(2.8)$ \\
\hline Technicians and associate professionals & $1(0.3)$ \\
\hline Clerical support workers & $8(2)$ \\
\hline Service and sales workers & $3(0.8)$ \\
\hline Skilled agricultural, forestry and fishery workers & $2(0.5)$ \\
\hline Craft and related trades workers & $3(0.8)$ \\
\hline Housewife & $303(77.3)$ \\
\hline Others & $61(15.6)$ \\
\hline Total & $392(100)$ \\
\hline \multicolumn{2}{|l|}{ Comorbids } \\
\hline Hypertensive & $309(84.4)$ \\
\hline IHD & $31(8.5)$ \\
\hline Dyslipidemia & $224(61.2)$ \\
\hline Diabetes & $300(82)$ \\
\hline Others & $135(36.9)$ \\
\hline \multicolumn{2}{|l|}{ Metabolic syndrome } \\
\hline Non-metabolic syndrome & $12(3.1)$ \\
\hline Metabolic syndrome & $366(93.4)$ \\
\hline Unknown & $14(3.6)$ \\
\hline
\end{tabular}

\section{TABLE 1: Characteristics of the study participants}

IHD, ischemic heart disease

More than three-quarters of the patients ( $n=303 ; 77.3 \%)$ were homemakers, while $89(22.7 \%)$ patients were doing any kind of job. Furthermore, comorbidities were present in all the patients. The most common comorbidity was hypertension $(\mathrm{n}=309 ; 84.4 \%)$ followed by diabetes $(\mathrm{n}=300 ; 82 \%)$ and dyslipidemia $(\mathrm{n}=$ $224 ; 61.2 \%)$.

Moreover, results showed that 366 (93.4\%) of the patients has MetS, 12 (3.1\%) were non-MetS, and 14 (3.6\%) 


\section{Cureus}

had unknown status due to incomplete information about the components of MetS (Table 2).

\begin{tabular}{|c|c|c|c|c|}
\hline \multirow{2}{*}{ Characteristics } & \multicolumn{2}{|c|}{ Metabolic syndrome } & \multirow{2}{*}{ Overall } & \multirow{2}{*}{ P-value } \\
\hline & No $(n=7)$ & Yes $(n=375)$ & & \\
\hline \multicolumn{5}{|l|}{ Age (in years) } \\
\hline Mean \pm SD & $47.2 \pm 13.5$ & $50.5 \pm 9.5$ & $50.5 \pm 9.6$ & \multirow{3}{*}{$0.749^{\ddagger}$} \\
\hline Min-Max & 30 to 60 & 24 to 79 & 24 to 79 & \\
\hline Median (IQR) & 55.5 (33 to 60$)$ & 50 (45 to 56 ) & 50 (45 to 56$)$ & \\
\hline \multicolumn{5}{|l|}{ Height (cm) } \\
\hline Mean \pm SD & $156.7 \pm 7$ & $154 \pm 7.9$ & $154.1 \pm 7.9$ & \multirow{3}{*}{$0.249^{\ddagger}$} \\
\hline Min-Max & 145 to 167.6 & 103 to 180 & 103 to 180 & \\
\hline Median (IQR) & 157.5 (152.5 to 160$)$ & 153 (149.5 to 158$)$ & 153 (150 to 158.8$)$ & \\
\hline \multicolumn{5}{|l|}{ Weight (kg) } \\
\hline Mean \pm SD & $78.8 \pm 13.7$ & $77.5 \pm 13.4$ & $77.6 \pm 13.5$ & \multirow{3}{*}{$0.571^{\ddagger}$} \\
\hline Min-Max & 60.4 to 95 & 50 to 130 & 50 to 130 & \\
\hline Median (IQR) & 80 (61.5 to 91$)$ & 75 (68 to 84$)$ & 75 (68 to 84.9$)$ & \\
\hline \multicolumn{5}{|l|}{ BMI } \\
\hline Mean \pm SD & $32 \pm 4.6$ & $32.7 \pm 5.7$ & $32.8 \pm 5.7$ & \multirow{3}{*}{$0.946^{\ddagger}$} \\
\hline Min-Max & 25.1 to 37.6 & 23.2 to 75.4 & 23.2 to 75.4 & \\
\hline Median (IQR) & 33.1 (28.5 to 36.7 ) & 31.9 (29.1 to 35.2$)$ & 31.9 (29.1 to 35.3$)$ & \\
\hline \multicolumn{5}{|c|}{ Waist circumference $(\mathrm{cm})$} \\
\hline Mean \pm SD & $39.8 \pm 4.5$ & $43 \pm 7$ & $43.2 \pm 7.7$ & \multirow{3}{*}{$0.080^{\ddagger}$} \\
\hline Min-Max & 36 to 47 & 32 to 142 & 32 to 142 & \\
\hline Median (IQR) & 38.8 (36 to 45$)$ & 42.3 (40 to 45 ) & 42.2 (40 to 45$)$ & \\
\hline \multicolumn{5}{|c|}{ Neck circumference $(\mathrm{cm})$} \\
\hline Mean \pm SD & $37.2 \pm 2.8$ & $37.9 \pm 3.9$ & $38 \pm 4.6$ & \multirow{3}{*}{$0.667^{\ddagger}$} \\
\hline Min-Max & 33 to 40.6 & 29 to 78.7 & 29 to 88.9 & \\
\hline Median (IQR) & 36.8 (35.6 to 40.6 ) & 38.1 (35.6 to 40.6 ) & 38.1 (35.6 to 40.6 ) & \\
\hline \multicolumn{5}{|c|}{ Systolic blood pressure $(\mathrm{mm}$ of $\mathrm{Hg})$} \\
\hline Mean \pm SD & $115.3 \pm 9.6$ & $129.6 \pm 16.6$ & $129.3 \pm 16.5$ & \multirow{3}{*}{$0.009^{*}$} \\
\hline Min-Max & 100 to 130 & 90 to 190 & 90 to 190 & \\
\hline Median (IQR) & 117 (110 to 120$)$ & 130 (120 to 140$)$ & $130(120$ to 140$)$ & \\
\hline \multicolumn{5}{|c|}{ Diastolic blood pressure $(\mathrm{mm}$ of $\mathrm{Hg}$ ) } \\
\hline Mean \pm SD & $71.4 \pm 3.8$ & $78.8 \pm 10.8$ & $78.6 \pm 10.7$ & \multirow{3}{*}{$0.038^{* 4}$} \\
\hline Min-Max & 70 to 80 & 60 to 110 & 60 to 110 & \\
\hline Median (IQR) & $70(70$ to 70$)$ & 80 (70 to 90$)$ & 80 (70 to 90$)$ & \\
\hline \multicolumn{5}{|c|}{ Fasting blood glucose } \\
\hline Mean \pm SD & $96.9 \pm 15.7$ & $147.8 \pm 61.3$ & $145.8 \pm 61$ & \multirow{3}{*}{$0.001^{* \neq}$} \\
\hline Min-Max & 87 to 130 & 43 to 438 & 43 to 438 & \\
\hline Median (IQR) & 90 (87 to 104$)$ & 132 (108 to 167.3$)$ & 129.5 (106 to 165.5$)$ & \\
\hline \multicolumn{5}{|l|}{ Total cholestrol } \\
\hline
\end{tabular}




\section{Cureus}

\begin{tabular}{|c|c|c|c|c|}
\hline Min-Max & 129 to 226 & 53 to 314.1 & 53 to 314.1 & $0.281^{\dagger}$ \\
\hline Median (IQR) & 197 (138.7 to 206 ) & 166 (135 to 196$)$ & 166.2 (136 to 197$)$ & \\
\hline \multicolumn{5}{|l|}{ Triglyceride } \\
\hline Mean \pm SD & $90.3 \pm 28.4$ & $167.7 \pm 81.1$ & $164.9 \pm 80.8$ & \multirow{3}{*}{$0.001^{4}$} \\
\hline Min-Max & 65 to 135 & 27 to 604.7 & 27 to 604.7 & \\
\hline Median (IQR) & 80 (65 to 118 ) & $150(116.3$ to 195.8$)$ & 147 (115 to 193.5$)$ & \\
\hline \multicolumn{5}{|l|}{$\mathrm{HDL}$} \\
\hline Mean \pm SD & $55 \pm 11.7$ & $38.5 \pm 9.7$ & $39.1 \pm 10.3$ & \multirow{3}{*}{$0.001^{4}$} \\
\hline Min-Max & 41 to 69.8 & 14 to 91 & 14 to 91 & \\
\hline Median (IQR) & $57(42.3$ to 69$)$ & 37.1 (32 to 43.5$)$ & 38 (32.5 to 44$)$ & \\
\hline \multicolumn{5}{|l|}{ LDL } \\
\hline Mean \pm SD & $119.3 \pm 35.5$ & $110.1 \pm 38.6$ & $110.3 \pm 38.2$ & \multirow{3}{*}{$0.398^{\ddagger}$} \\
\hline Min-Max & 63 to 157 & 25 to 228 & $25-228$ & \\
\hline Median (IQR) & $128(78.6-151)$ & 105 (81 to 137.7$)$ & 106 (81.2 to 137$)$ & \\
\hline \multicolumn{5}{|c|}{ VLDL-Cholesterol } \\
\hline Mean \pm SD & $18 \pm 5.8$ & $34 \pm 18.5$ & $33.4 \pm 18.4$ & \multirow{3}{*}{$0.001^{4}$} \\
\hline Min-Max & 13 to 27 & 5 to 206 & 5 to 206 & \\
\hline Median (IQR) & 16 (13 to 24$)$ & 30 (23 to 39.3 ) & 29 (23 to 39 ) & \\
\hline \multicolumn{5}{|c|}{ Non-HDL Cholesterol } \\
\hline Mean \pm SD & $130.4 \pm 40$ & $129.1 \pm 42.2$ & $128.8 \pm 41.9$ & \multirow{3}{*}{$0.736^{\ddagger}$} \\
\hline Min-Max & 69 to 169 & 35 to 273 & 35 to 273 & \\
\hline Median (IQR) & 140 (80 to 162$)$ & 127 (97 to 155.3 ) & 127.5 (97 to 155.2 ) & \\
\hline \multicolumn{5}{|l|}{ HbA1c } \\
\hline Mean \pm SD & $5.4 \pm 0.6$ & $8 \pm 2$ & $7.9 \pm 2$ & \multirow{3}{*}{$0.000^{*+4}$} \\
\hline Min-Max & 4.6 to 6.3 & 4.1 to 14.9 & 4.1 to 14.9 & \\
\hline Median (IQR) & $5.4(4.8$ to 6$)$ & 7.5 (6.4 to 9.2 ) & 7.5 (6.3 to 9.1 ) & \\
\hline \multicolumn{5}{|l|}{ Comorbid } \\
\hline Hypertensive & $2(28.6)$ & $316(84.3)^{\mathrm{a}}$ & 324 (82.7) & \multirow{5}{*}{$0.000^{* *+1}$} \\
\hline $\mathrm{IHD}$ & $0(0)$ & $32(8.5)$ & $33(8.4)$ & \\
\hline Dyslipidemia & $6(85.7)$ & $224(60.3)$ & $233(59.4)$ & \\
\hline Diabetes & $1(14.3)$ & $303(80.8)^{\mathrm{a}}$ & $304(77.6)$ & \\
\hline Others & 5 (71.4) & $141(37.6)$ & 154 (39.3) & \\
\hline
\end{tabular}

TABLE 2: Characteristics of the study participants with and without metabolic syndrome

SD, standard deviation; IQR, interquartile range; IHD, ischemic heart disease, HDL, high-density lipoprotein; HbA1c, glycated hemoglobin

It was observed that $90 \%$ of both males and females had $\mathrm{NC} \geqslant 38 \mathrm{~cm}$ and $34 \mathrm{~cm}$, respectively, and the optimal cutoff values were provided by Hingorjo MR et al. [16]. Also, females had lower NC than males (mean \pm SD: $37.5 \pm 3.7 \mathrm{~cm}$ vs $41.4 \pm 3.2 \mathrm{~cm}, \mathrm{p}<0.0001)$.

Additionally, no significant linear correlation was between NC and HbA1C, total cholesterol, LDL, non-HDL cholesterol, fasting blood glucose levels, and SBP and DBP. A significant weak positive correlation was 


\section{Cureus}

observed between NC and WC, VLDL cholesterol, and TG; however, a significant weak negative correlation was observed between NC and female gender and HDL (Table 3).

\begin{tabular}{|c|c|c|c|}
\hline & Unadjusted correlation coefficient & P-value & Adjusted correlation coefficient \\
\hline Females & -0.329 & $0.000^{* *}$ & - \\
\hline BMI & 0.184 & $0.000^{\star *}$ & $0.201^{\star *}$ \\
\hline Waist circumference in $\mathrm{cm}$ & 0.290 & $0.000^{* *}$ & $0.293^{\star *}$ \\
\hline TG & 0.107 & $0.020^{*}$ & 0.112 \\
\hline HDL & -0.123 & $0.008^{*}$ & -0.087 \\
\hline VLDL cholesterol & 0.106 & $0.023^{\star}$ & 0.109 \\
\hline HBA_RESULT & 0.069 & 0.138 & 0.088 \\
\hline Total cholesterol & -0.068 & 0.140 & -0.051 \\
\hline LDL & -0.069 & 0.134 & -0.058 \\
\hline Non-HDL cholesterol & -0.039 & 0.394 & -0.030 \\
\hline Fasting blood glucose & 0.037 & 0.422 & 0.059 \\
\hline Systolic $(\mathrm{mm}$ of $\mathrm{Hg})$ & 0.019 & 0.695 & 0.011 \\
\hline Diastolic (mm of Hg) & 0.002 & 0.966 & -0.012 \\
\hline
\end{tabular}

TABLE 3: Correlation of neck circumference with various variables

BMI, body mass index; TG, triglyceride; HDL, high-density lipoprotein; VLDL, very low density lipoprotein; LDL, low-density lipoprotein

On the contrary, NC was found to be significantly positively correlated with BMI and WC only adjusting for gender (Table 3).

\section{Discussion}

The National Nutrition Health Survey (2018) of Pakistan reported a high prevalence of overweight and obesity in adolescents, young adults, and women of reproductive age [19]. Moreover, the prevalence of MetS has increased two folds over the last 10 years in Pakistan, indicating that these two are the emerging public health issues in Pakistan that require urgent attention of healthcare providers to restrain their increasing incidence [7-8]. Although Pakistan is facing an epidemic of obesity and MetS, no recent literature is available assessing the burden of MetS in general as well as in the overweight and obese population.

In this study, we found a very high prevalence of MetS (95.7\%) in our overweight and obese patients in comparison to the previous studies done in Pakistan [5,7-8,20]. Also, in our study, the majority of patients were diabetic and hypertensive, which is one of the diagnostic components of MetS. Ahmed A et al. (2012) reported $91.9 \%$ prevalence of MetS in type 2 diabetic patients, whereas other studies reported a high prevalence of overweight and obesity among MetS patients [5,7,19]. Moreover, a wide variation in the prevalence of MetS has been reported in various developing countries, i.e., from $7.9 \%$ to 39\% [21]. This enormous heterogeneity in the prevalence could be due to the different criteria used for MetS, ethnic variations, genetics, environmental and cultural differences, study settings, and other risk factors. Also, patients presenting to the Indus Hospital belong to low- and middle socioeconomic groups that could account for the high prevalence of MetS. Literature reports an association between low socioeconomic status (SES) and MetS as people belonging to low SES are less educated, have low healthcare knowledge, and less leisure-time physical activity and may be unemployed [22-23].

Furthermore, our study revealed that more than $90 \%$ of our study participants had NC greater than or equal to the optimal cut-off values provided by Hingorjo MR et al. [17]. Thus, this indicates that these cut-off values can be used to screen MetS in the Pakistani population, thereby reducing the diagnostic testing. Several studies have reported the use of NC for identifying obesity and MetS by various criteria in different populations $[10,15,18,24-25]$.

Additionally, we found a significant positive association between NC and VLDL and TG. This result is also supported by a recent systematic review and meta-analysis [16]. Some of the components of MetS in our 
study were not significantly correlated with NC, which include HbA1c, SBP and DBP, TC, LDL, non-HDL, and fasting glucose levels, whereas Bochaliya et al., Cho et al., Ben-Noun, and Ataie Jafari showed significant association of these aforementioned variables with NC [23,26-28]. It was also shown by Ravikiran et al. that the risk of cardiovascular diseases and MetS among South Asians increased due to an increase in fat mass of intra-abdomen, body, and truncal subcutaneous and ectopic deposition, such as the region of the neck [29]. In our study, BMI and WC were significantly associated with NC. The significant association between NC and BMI and WC was observed in other studies as well, which identified NC as an efficient tool for the identification of patients with obesity and MetS [10,30]. Therefore, our study is in agreement with other studies that suggest NC as a good predictor of obesity and MetS.

\section{Limitations}

Since this study was a cross-sectional study, we could not establish an association between MetS and NC. We suggest either a longitudinal or a case-control study to establish any relationship between MetS and NC. Secondly, this is a single-center, hospital-based study with the majority of patients being females. Thirdly, in this study, we have included all the overweight and obese patients, out of which almost two-thirds were both diabetic and hypertensive, which are the components contributing to MetS due to which we found a very high prevalence of MetS. We recommend further community-based studies to assess the burden of the disease.

\section{Conclusions}

A very high prevalence of MetS was observed among overweight and obese patients in this study. Moreover, NC can be used as a screening tool for MetS.

\section{Additional Information \\ Disclosures}

Human subjects: Consent was obtained by all participants in this study. Interactive research development institutional review board issued approval IRD_IRB_2018_05_010. The above-referenced human subjects research project has been approved by the IRD-IRB. This approval is limited to the activities described in the study protocol and extends to the performance of these activities at each respective site identified in the application for IRB Review. It is inclusive of all previously approved documents. As principal investigator for a study involving human subjects, you assume certain responsibilities, specifically: 1 . You will conduct the study according to the protocol approved by the IRB. As the PI, you will be accountable for your own research and the protection of human subjects. You will ensure, at all times, that you have the appropriate resources and facilities to conduct the study. You will ensure that all research personnel involved in the conduct of the study have been appropriately trained on the protection of human subjects, in addition to the study procedures. 2. Any unanticipated problems involving risks to participants or others will be reported to the IRB in accordance to the IRB policy. Changes in approved research initiated without IRB approval to eliminate apparent immediate hazards to the participant, are to be reported to the IRB. 3. Any changes in your research plan must be submitted to the IRB for review and approval prior to implementation of the change. Proposed changes in approved research cannot be initiated without IRB approval, except when necessary to eliminate apparent immediate hazards to participants. 4. A Progress Report for continuing review or a Study Closure Form, as applicable, must be submitted to the IRB administration by the administrative due date in order to allow sufficient time for review/closure to be completed prior to the expiration date. Failure to attain continued renewal by the expiration date will result in the study being assigned an inactive status, whereby all research activities including data analysis must stop immediately. . Animal subjects: All authors have confirmed that this study did not involve animal subjects or tissue. Conflicts of interest: In compliance with the ICMJE uniform disclosure form, all authors declare the following: Payment/services info: All authors have declared that no financial support was received from any organization for the submitted work. Financial relationships: All authors have declared that they have no financial relationships at present or within the previous three years with any organizations that might have an interest in the submitted work. Other relationships: All authors have declared that there are no other relationships or activities that could appear to have influenced the submitted work.

\section{Acknowledgements}

We acknowledge Dr Naila Baig-Ansari, Chair, Indus Hospital Research Center for helping us in the entire research process.

\section{References}

1. Siddiqui M, Hameed R, Nadeem M, et al.: Obesity in Pakistan; current and future perceptions . J Curr Trends Biomed Eng Biosci. 2018, 17:001-004.

2. Hingorjo MR, Qureshi MA, Mehdi A: Neck circumference as a useful marker of obesity: a comparison with body mass index and waist circumference. J Pak Med Assoc. 2012, 62:36.

3. Herningtyas EH, Ng TS: Prevalence and distribution of metabolic syndrome and its components among provinces and ethnic groups in Indonesia. BMC Public Health. 2019, 19:377-10. https://doi.org/10.1186/s12889-019-6711-7I

4. Liu J, Grundy SM, Wang W, et al.: Ethnic-specific criteria for the metabolic syndrome: evidence from China . Diabetes Care. 2006, 29:1414-1416.

5. Ahmed A, Khan TE, Yasmeen T, Awan S, Islam N: Metabolic syndrome in type 2 diabetes: comparison of 
WHO, modified ATPIII \& IDF criteria. J Pak Med Assoc. 2012, 62:569-574.

6. Basit A, Shera AS: Prevalence of metabolic syndrome in Pakistan. Metab Syndr Relat Disord. 2008, 6:171175.

7. Iqbal Hydrie MZ, Shera AS, Fawwad A, Basit A, Hussain A: Prevalence of metabolic syndrome in urban Pakistan (Karachi): comparison of newly proposed International Diabetes Federation and modified Adult Treatment Panel III criteria. J Metab Syndr. 2009, 7:119-124.

8. Ali NS, Khuwaja AK, Adnan Ur R, Nanji K: Retrospective analysis of metabolic syndrome: prevalence and distribution in executive population in urban pakistan. Int J Family Med. 2012, 2012: 649383. 10.1155/2012/649383I,

9. The Global Burden of Disease: Generating Evidence, Guiding Policy. South Asia Regional Edition . (2013). Accessed: November 7, 2019:

http://www.healthdata.org/sites/default/files/files/data_for_download/2013/WorldBank_SouthAsia/IHME_GBD_WorldBank_Sc

10. Lin S, Hu L, Li P, et al.: Utility of neck circumference for identifying metabolic syndrome by different definitions in Chinese subjects over 50 years old: a community-based study. J Diabetes Res. 2018, 2018:3708939.

11. Sagun G, Oguz A, Karagoz E, Filizer AT, Tamer G, Mesci B: Application of alternative anthropometric measurements to predict metabolic syndrome. Clinics (Sao Paulo). 2014, 69:347-353.

12. Verma M, Rajput M, Sahoo SS, Kaur N: Neck circumference: independent predictor for overweight and obesity in adult population. Indian J Community Med. 2017, 42:209-213.

13. Silva CdCd, Zambon MP, Vasques ACJ, et al.: Neck circumference as a new anthropometric indicator for prediction of insulin resistance and components of metabolic syndrome in adolescents: Brazilian Metabolic Syndrome study. Revista Paulista de Pediatria. 2014, 32:221-229.

14. Kurtoglu S, Hatipoglu N, Mazicioglu MM, Kondolot M: Neck circumference as a novel parameter to determine metabolic risk factors in obese children. Eur J Clin Invest. 2012, 42:623-630.

15. Luo Y, Ma X, Shen Y, et al.: Neck circumference as an effective measure for identifying cardio-metabolic syndrome: a comparison with waist circumference. Endocrine. 2017, 55:822-830.

16. Namazi N, Larijani B, Surkan PJ, Azadbakht L: The association of neck circumference with risk of metabolic syndrome and its components in adults: A systematic review and meta-analysis. Nutr Metab Cardiovasc Dis. 2018, 28:657-674. 10.1016/j.numecd.2018.03.006I

17. Hingorjo MR, Zehra S, Imran E, Qureshi MA: Neck circumference: a supplemental tool for the diagnosis of metabolic syndrome. J Pak Med Assoc. 2016, 66:1221-1226.

18. Llido L, Mirasol R: Comparison of body mass index based nutritional status using WHO criteria versus “Asian” criteria: report from the Philippines. J Parenter Enteral Nutr. 2011, 1-8.

19. Pakistan National Nutrition Survey 2018 - Key Findings Report. (2018). Accessed: November 7, 2018: https://www.unicef.org/pakistan/media/1951/file/Final\%20Key\%20Findings\%20Report\%202019.pdf.

20. Jahan F, Qureshi R, Borhany T, Hamza HB: Metabolic syndrome: frequency and gender differences at an out-patient clinic. J Coll Physicians Surg Pak. 2007, 17:32.

21. Yu S, Guo X, Yang H, Zheng L, Sun Y: An update on the prevalence of metabolic syndrome and its associated factors in rural northeast China. BMC Public Health. 2014, 14:877-10.

22. Yang X, Tao Q, Sun F, Zhan S: The impact of socioeconomic status on the incidence of metabolic syndrome in a Taiwanese health screening population. Int J Public Health. 2012, 57:551-559.

23. Cho NH, Oh TJ, Kim KM, et al.: Neck circumference and incidence of diabetes mellitus over 10 years in the Korean Genome and Epidemiology Study (KoGES). Sci Rep. 2015, 5:18565-10.

24. Joshipura K, Muñoz-Torres F, Vergara J, Palacios C, Pérez CM: Neck circumference may be a better alternative to standard anthropometric measures. J Diabetes Res. 2016, 2016:6058916.

25. Vallianou NG, Evangelopoulos AA, Bountziouka V, et al.: Neck circumference is correlated with triglycerides and inversely related with HDL cholesterol beyond BMI and waist circumference. Diabetes Metab Res Rev. 2013, 29:90-97.

26. Bochaliya RK, Sharma A, Saxena P, Ramchandani GD, Mathur G: To evaluate the association of neck circumference with metabolic syndrome and cardiovascular risk factors. J Assoc Physicians India. 2019, 67:60-62.

27. Ben-Noun LL, Sohar E, Laor A: Neck circumference as a simple screening measure for identifying overweight and obese patients. Obesity. 2001, 9:470-477.

28. Ataie-Jafari A, Namazi N, Djalalinia S, et al.: Neck circumference and its association with cardiometabolic risk factors: a systematic review and meta-analysis. Diabetol Metab Syndr. 2018, 10:72-10.

29. Ravikiran M, Bhansali A, Ravikumar P, et al.: Prevalence and risk factors of metabolic syndrome among Asian Indians: a community survey. Diabetes Res Clin Pract. 2010, 89:181-188.

30. Anothaisintawee T, Sansanayudh N, Thamakaison S, Lertrattananon D, Thakkinstian A: Neck circumference as an anthropometric indicator of central obesity in patients with prediabetes: a cross-sectional study. BioMed Research International. 2019, 2019: 